\title{
Kulturni turizem
}

\author{
Irena Weber \\ UP Fakulteta za turistične študije - Turistica \\ irena.weber@fts.upr.si \\ Katja Hrobat Virloget \\ uP Fakulteta za humanistične študije \\ katja.hrobat@fhs.upr.si \\ Aleš Gačnilk \\ uP Fakulteta za turistične študije - Turistica \\ ales.gacnik@fts.upr.si
}

\section{Uvod: kulturni turizem med holizmom in (modnim) pridevnikom}

Primerjalni pregled dveh obsežnejših monografij o kulturnem turizmu (Smith in Richards, 2013; Du Cros in McKercher, 2015) nam precej hitro razkrije dva izrazito različna pristopa $\mathrm{k}$ razumevanju, raziskovanju in interpretaciji kulturnega turizma, ki sta tudi sicer značilna za polje turističnih študij. Manjšinski, izhajajoč iz tradicije humanistike in kritičnega družboslovja, ki prevprašuje sam koncept kulture in raziskave, se opira na izbrane kulturne teorije v poljih različnih disciplin, kot so zgodovina, antropologija, sociologija kulture, kulturna geografija, filozofija, kulturni študiji, obravnava problematiko kulturnega turizma multidisciplinarno, holistično in s podmeno, da 
je turizem, v tradiciji Maussovega znamenitega Eseja o daru, „totalni družbeni fenomen« (1996, str. 11). Drugi, večinski pristop v polju turističnih študijev je poslovni, upravljalski in tržni, turizem prevladujoče razume kot industrijo, ekonomsko panogo in parcialni fenomen, v kolikor ga, kot fenomen, sploh obravnava. Kulturo povečini enači $\mathrm{s}$ kulturno dediščino, natančneje $\mathrm{z}$ upravljanjem in s trženjem kulturne dediščine. Kjer prvi pristop poudarja kulturo kot proces, z izrazito historično dimenzijo, jo drugi izpostavlja kot produkt, pri katerem je historičnost običajno abstrahirana. Dominantnost poslovnih, upravljalskih in trženjskih raziskav kulturni turizem vzpostavlja kot nišo znotraj ublagovljene kulture, namenjene potrošnji, kar posledično spodbuja večji obseg raziskav vedenja potrošnikov, meritve frekvenc obiskov in kategorizacijo motivacij in tipov (kulturnih) potrošnikov ipd. Komodifikacijo ${ }^{1}$ kulture tako nekateri avtorji (Smith idr., 2012) obravnavajo kot proces, v katerem se kulturi, v snovni in nesnovni obliki, odvzame pomen in se jo predrugači v blago, oziroma kot produkt, ki se predstavlja pod znamko »kulturnega turizma«. Tudi historična kategorija gostoljubja, denimo, ki v klasični antropološki presoji izpostavlja izmenjavo, obvezo recipročnosti in kompleksne kulturne vzorce, kot jih je mogoče uvideti tudi skozi izbrane primere likovne umetnosti (Selwyn, 2013), je v poslovnem kontekstu prvenstveno zvedena na razmerje ponudbe in povpraševanja $\mathrm{v}$ nastanitvenih obratih, kjer je gostoljubje komercialna kategorija. Poleg izhodiščne razlike $v$ pojmovanju kulture, tj. kot procesa ali produkta, je omembe vredno nasprotje med obema zgoraj omenjenima pristopoma razumevanje kulture kot fluidne na eni in kot relativno zamejene statične entitete na drugi strani; fluidna kultura se v turističnem trženju »zlahka« razloči od druge, domnevno zamejene statične entitete $\mathrm{v}$ spornem procesu drugačenja.

V pričujočem besedilu se v obravnavi kulture, kot koncepta in kulturnega turizma, prvenstveno naslanjamo na tradicijo antropologije in etnologije, zato v prvem delu odpiramo dileme, kontroverze in zagate $\mathrm{z}$ definiranjem in razumevanjem kulture ter kulturnega turizma, nadaljujemo s kritično analizo kompleksnih povezav dedi-

1. Izraz »komodifikacija« je v slovenščini v rabi v dveh oblikah: »ublagovljenje« in "poblagovljenje«. Izraza sta enakovredna in nimata različnih konotacij. Gre za posledico različnih prevajanj Marxovega pojma, ki se veže na analizo produkcijskih načinov. 
ščine in turizma ter v zadnjem, (p)odpremo pridevniško obliko ali pomemben participatorni fragment znotraj kulturnega turizma, $t$ i. kreativni turizem. Na ta način se, med drugim, poklonimo turizmu kot "privrženemu častilcu mode«, ki je enkrat v pikah in že naslednji teden v črtah, vzetih iz zakladnice popularne kulture iz sredine šestdesetih minulega stoletja (The Kinks, 1965). Kritiko fragmentacije in hiperprodukcije pridevniških turizmov ob hkratni rabi pridevniškega turizma v kontekstu pričujoče monografije razumemo kot klasičen paradoks.

\section{Problem definicije in rabe koncepta kulture \\ ter kulturnega turizma}

Etimološko kultura izhaja iz latinske cultura, ki je izpeljanka iz korenskega izraza colere s pahljačo pomenov, kot so: obdelovati, prebivati, naseljevati, negovati, gojiti, učiti, skrbeti za, vzgajati, obhajati. Pomeni so se sčasoma razvejali, a ohranili tudi prekrivanje. Tako je, denimo, iz pomena naselitve, izpeljan izraz colonus, iz tega kolonija in iz čaščenja cultus, se pravi kult. Kultura, kot je poudaril že Williams (1958), je v svojih izvornih pomenih vedno izražala procesualnost, naj je šlo za obdelovanje zemlje, sajenje, gojenje in pridelovanje, vse torej, kar vežemo z agri, ali izobraževanje, vzgojo in plemenitenje, kar je Cicero povezal z animi, s kultiviranjem duše. Prvotno je bil pomen kulture prevladujoče in neposredno vezan na obdelovanje zemlje, na kultivirano krajino in kulturne rastline. V 15. stoletju dobi figurativni pomen kultiviranja ljudi s pomočjo izobraževanja. Še danes lahko rečemo, da je pravilno »(vz)gojen« in "obdelan« človek »kultiviran«. S tem izrazom običajno naglasimo izbornost izražanja, uglajenost, omikanost, znanje.

Kultura dobi pomen kolektivnih dosežkov in navad v 19. stoletju in se v tem obdobju neločljivo povezuje s pojmom civilizacije. Za eno najširše sprejetih definicij še vedno velja Tylorjeva s konca 19. stoletja, ki pravi, da je »Kultura oziroma Civilizacija tista kompleksna celota, ki vključuje znanje, verovanje, umetnost, moralo, običaje in še vse ostale sposobnosti in navade, ki jih človek pridobi kot član družbe« (1871, str. 1). Poenostavljeno in učbenikom primerno jo je norveški antropolog Eriksen (2001, str. 12) skrajšal v »kultura je skupek tistih sposobnosti, predstav in oblik vedenja, ki so si jih ljudje pridobili kot člani družbe«. V sodobnosti unesco (2011) Tylorjevo definicijo kulture sprejema tako rekoč v celoti, izpušča le besedo civiliza- 
cija oziroma enačenje kulture s civilizacijo. Zakaj in na kakšen način je prišlo do razločitve teh dveh pojmov in vprašanje, ali je ta ločitev dejansko produktivna, je predmet bolj poglobljene zgodovinske analize, ki za obravnavo kulturnega turizma sicer ni prvenstvenega pomena, gotovo pa ni irelevantna.

Kroeber in Kluckhohn (1952) sta v vplivni pregledni študiji naštela kar 161 definicij kulture, od katerih so si bile mnoge resda podobne, vendar število samo po sebi odraža zagate iskanja ene ali enotne definicije.

Problem definiranja kulture in njenih interpretacij dobi še dodatno razsežnost, ko izstopimo iz tradicije evropskih jezikov in, na primer, pogledamo »kulturo«v kontekstu kitajske filozofije, načina mišljenja in vrednot. Kitajski izraz wenhua (文化), ki se v sodobnosti prevaja oziroma transliterira kot »kultura«, sicer pa celostno označuje »transformacijo narave in družbe skladno s človeškimi potrebami« (Fang, 2019, str. 10), je sestavljen iz wen, ki med drugim pomeni »dobrohotno vladanje«, in hua, "pripravljenost za življenje v civiliziranem svetu« (str. 10). Na tem mestu se zaradi omejenega prostora in namena besedila sicer ne moremo spuščati v podrobnosti kitajske kompleksnosti sestavljanja pomenov in kulturnih vplivov Evrope 19. stoletja, ki so vplivali na tradicionalno konfucijansko pojmovanje "kulture«, vendar lahko ugotovimo, da se v sodobnih procesih komodifikacije kulture tovrstne problematike premalo pogosto in premalo poglobljeno naslavljajo. V veliki meri temu botrujeta dominantna kulturna hegemonija Zahoda in globalna raba angleškega jezika, obvladujoča veliko in vplivno produkcijo akademskih besedil, ki koncept kulture razumejo, bolj ali manj, v kontekstu evropocentrizma ali katerega od drugih zahodnih centrizmov. Kultura in kulturni turizem se prevladujoče, "samoumevno«, uporabljata v kontekstu evropske tradicije in interpretacije.

Tylorjeva definicija kljub preživetveni trdoživosti na splošno velja za preveč vseobsegajočo, zato se je raba pojma kulture v dvajsetem stoletju, v zahodni tradiciji, obravnavala v vsaj v treh distinktivnih oblikah. Utemeljitelj kulturnih študijev Williams (1958; 1983) jih je opredelil od širokega do ozkega pomena, kot ideal, dokument ali pričevanje, ter kot intelektualno in umetniško prakso. Prva oblika kulturo povezuje s splošnim procesom intelektualnega, duhovnega in estetskega razvoja določenega območja; tako govorimo, na primer, o kulturnem razvoju Evrope ali Azije, Afrike ipd. Druga oblika izpo- 
stavlja specifičen način življenja v nekem obdobju ali specifično življenje neke skupine, ljudstva, naroda. Govorimo o neolitski kulturi, srednjeveški kulturi, romski kulturi, masajski kulturi, kitajski kulturi itd. Tretja oblika je tista, ki je najbolj razširjena v vsakdanji rabi in se veže predvsem na umetniško aktivnost in produkcijo ter produkcijo pomenov. To obliko pokrivajo množični mediji pod razdelkom »kultura» in »kulturne prireditve« ter pogosto spada pod okrilje aktivnosti in upravljanja ministrstev za kulturo.

T. i. "kulturni obrat" v humanistiki in družboslovju zgodnjih sedemdesetih let minulega stoletja je bil odmik od pozitivistične epistemologije in je koncept kulture postavil v središče zanimanja različnih ved, disciplin in raziskovalnih področij, ob sočasnem razvoju poststrukturalističnih teorij, ki so koncept kulture dekonstruirale. Pod vplivom Foucaulta in Derridaja je, denimo, tudi Bauman (1999) na novo razmislil svojo analizo kulture kot koncepta, strukture in prakse. Posledica dekonstrukcije koncepta kulture je bil, med drugim, tudi odmik od antropoloških obravnav kulture kot nečesa kompleksnega, a jasno zamejenega, v smeri razumevanja kulture kot procesa, kar nas, $\mathrm{v}$ določeni meri, vrača $\mathrm{k}$ izvornim pomenom kultivacije. Sodobne razprave o hibridnosti ali kreolizaciji sicer še vedno vsebujejo in ohranjajo podmeno primordialno »čistih kulturnih oblik«, ki se "mešajo«. Kultura torej ostaja ambivalenten, heterogen in mnogokrat sporen koncept, ki se, še posebej v turističnih študijih, pogosto uporablja esencialistično in redukcionistično.

$\mathrm{Z}$ ozirom na zagate $\mathrm{s}$ konceptom in $\mathrm{z}$ razumevanjem kulture ni presenetljivo, da tudi za kulturni turizem nimamo ene ali vsaj prevladujoče definicije. Definicije so heterogene in odražajo tako temeljne delitve v turističnih študijih, ki smo jih obravnavali, kot naraščajočo množičnost, o kateri bo govora kasneje. Najprej si poglejmo tri institucionalne definicije.

Vsebinsko najožja je definicija je International Cultural Tourism Charter (International Council on Monuments and Sites, 1999), ki kulturni turizem opredeljuje kot tisto »obliko turizma, katere cilj je med drugim odkrivanje spomenikov in najdišč«. International Council on Monuments and Sites meni, da ta oblika turizma lahko pozitivno vpliva na vzdrževanje spomenikov, ki naj bi posledično pozitivno vplivali tako na turiste kot na lokalno skupnost. Ta definicija je torej na nek način »interesna « definicija, ki izpostavlja izjemno ozek segment opredeljene snovne kulturne dediščine. 
Najnovejša definicija Svetovne turistične organizacije (World Tourism Organization, b.l.), kot je to običajno za motivacijsko naravnane definicije, najprej izpostavlja motive turistov: »Kulturni turizem je vrsta dejavnosti, pri kateri je prvenstvena motivacija obiskovalca, da na turistični destinaciji spozna, odkrije, doživi in užije snovne in nesnovne znamenitosti/produkte ...«V nadaljevanju "pojasni«, na kaj se nanašajo kulturne znamenitosti/produkti:»[N]a nabor posebnih materialnih, intelektualnih, duhovnih in čustvenih značilnosti družbe, ki zajema umetnost in arhitekturo, zgodovinsko in kulturno dediščino, kulinarično dediščino, literature, glasbo, kreativne industrije in žive kulture z njihovimi življenjskimi slogi, vrednostnimi sistemi, prepričanji in tradicijami.«

Poleg problematičnosti izhodiščne osrediščenosti na turista, ki je v globalnem razmerju turizma strukturno privilegiran, je pri tej definiciji še posebej zanimiva tavtologija, podvojitev arhitekture, glasbe, umetnosti itd., kar je zajeto tudi v kreativnih industrijah, ter pomenljivost razločitve zgodovinske, kulturne in kulinarične dediščine.

Temeljne delitve pristopov v polju turističnih študijev, ki smo jih že omenili, neposredno določajo tudi oblike in vrste definicij v strokovni in znanstveni literaturi. Kot v preglednem članku o kulturnem turizmu ugotavljata T. Orel Frank in Z. Medarić (2018), so definicije tehnične ali deskriptivne, s poudarkom na produktih in tipih, ter konceptualne, s poudarkom na motivih, torej osredotočene na turiste. Avtorici ugotavljata tudi, da so nekatere druge pridevniške oblike turizma zvedene ali izenačene s kulturnim turizmom, kot na primer "etnični turizem«, za katerega navajata primer raziskave s Kitajske (str. 106).

Kitajsko pojmovanje kulturnega turizma ima sicer širšo konotacijo, vendar je iz njega možno tudi nedvoumno razbrati, zakaj so etnični vidiki lahko neposredno vključeni. Kadar pismenkama wenhua (文化), se pravi »kulturi«, dodamo lîu (旅) in yóu(遊), dobimo izraz

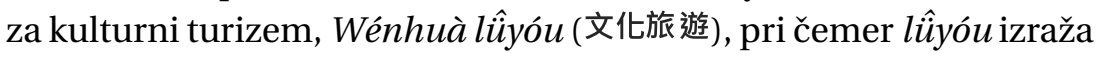
tako turizem kot pot, popotovanje, potovanje po morju ali kopnem in zraku ter izlet. Če nadalje upoštevamo, da pismenka hua (化), kadar je združena z wen (文), označuje situacijo, v kateri se za eno ali obe strani dogodi neka sprememba, ki je posledica stika obeh strani (Fang 2019, str. 9), potem lahko ugotovimo, da konceptualno kitajski izraz »kultura« razpira eksplicitno polje, v katerem sta prisotna stik in sprememba, medtem ko je v definiciji sto naglašen stik, ki iz- 
postavlja predvsem turista, medtem ko sprememba ni prisotna niti implicitno.

Za zaključek pregleda definicij poglejmo unesco-vo definicijo kulturnega turizma, ki je, v primerjavi z definicijo kulture, precej kratka in govori zgolj o »razločujočem tipu turizma, ki upošteva kulturo drugih ljudi« (UNESCO, 2008). Ob tem sicer v številnih arhivskih dokumentih in publikacijah izpostavlja tudi svoje poslanstvo pomoči državam članicam v prizadevanjih oblikovanja politik kulturnega turizma v smeri ohranitve »kulturne diverzitete«, »avtentičnosti življenja in "monumentalne dediščine« ter povezav kulture s trajnostnim razvojem (UNeSCO, 2014). Vse omenjene sintagme, prvi dve še posebej, sta v nadaljevanju, deležni kritičnega premisleka.

\section{Dediščina v turizmu}

Kultura in turizem sta bila vedno neločljivo povezana. Sicer strokovnjaki začetke kulturnega turizma postavljajo $\mathrm{v}$ čas po drugi svetovni vojni, njegov razmah pa v 80. in 9o. leta 20. stoletja, ko pride do »izbruha dediščine«. Dediščinski turizem naj bi bil ena izmed vej kulturnega turizma, praktično pa ju je nemogoče razlikovati (Richards, 2018a, str. 12-14).

Zakonodajno se dediščina deli na materialno, premično in nepremično ter nesnovno dediščino. Nadaljnja je zakonodajna delitev po strokah, kar pa je omejevalno, saj je do dediščine potrebno pristopati interdisciplinarno. Omejujoča je tudi delitev na naravno in kulturno dediščino, saj je večji del naravne dediščine kot posledica človekovega delovanja v okolju kulturna dediščina, zato se pridevnik kulturna opušča v prid izrazu dediščina (Bogataj, 1992, str. 13-14).

Po mnenju večine raziskovalcev je pojem dediščine nastal v času nastajanja nacionalnih držav in vzpona nacionalizma konec 19. stoletja in začetek 20. stoletja, ko se je oblikoval termin nacionalna dediščina, s čimer se je preteklost nacionalizirala. Nastajajoče nacije so za utrditev nacionalnih identifikacij, prepoznavnost in oblikovanje občutka povezanosti ter soglasnosti državljanov potrebovale materialne vire, zato je država prevzela skrb za nacionalno dediščino in vzgojo o njenem pomenu (Fakin Bajec, 2011, str. 63-65; Smith, 2006, str. 22). Evropocentrično razumevanje je dediščino omejevalo le na materialni del, saj se je prek pravnih aktov urejalo v glavnem le varovanje kulturnih spomenikov in umetnin. Pojmovanje dediščine kot univerzalne vrednote vsega človeštva je povezano z organizacijo 
UNESCO, ki je po drugi svetovni vojni stremela k njenemu ohranjanju in zaščiti. Odraz tega je leta 1972 sprejeta konvencija o varovanju svetovne kulturne in naravne dediščine (UNESCO, 1972). Ta udejanja zahodnjaško percepcijo dediščine ter evropocentričen pogled, ki dediščino definira kot materialno, monumentalno, veliko, »dobro«, estetsko (Fakin Bajec, 2011, str. 66-68; Smith, 2006). Kot protiutež temu neravnovesju je bila (šele) leta 2003 sprejeta unEsco-va konvencija o varovanju nesnovne kulturne dediščine (UNESCO, 2003), in sicer kot poskus priznanja nezahodnjaških manifestacij praks in dediščine, izhajajoč predvsem iz azijskih, afriških, južnoameriških in staroselskih dediščinskih praks (Smith in Akagawa, 2009, str. 1-4). Konvencija nesnovno dediščino deli na ustna izročila in izraze, vključno z jezikom, uprizoritvene umetnosti, družbene prakse, rituale in praznovanja, znanje in prakse o naravi ter svetu in tradicionalne obrtne veščine (Koželj, 2005, str. 10). Če je zahodnjaška ideja dediščine izhajala iz arhitekturne in arheološke diskusije o konservaciji in ohranjanju, je eno glavnih vprašanj pri nesnovni dediščini, kako upravljati dediščino, ki je spremenljiva in je del »žive kulture«, ne da bi jo fosilizirali, zamrznili ali banalizirali (Smith in Akagawa, 2009, str. 2-4).

V sodobnih premislekih se dediščino vse bolj dojema kot kulturno prakso in ne le kot mesto, nesnovno izvedbo ali dogodek (Smith in Akagawa, 2009, str. 6). Dediščina danes ni več razumljena kot fizični artefakt ali zapis, temveč kot kulturni proces. Sama po sebi ne obstaja, temveč jo ustvarimo prek »dediščenja» (angl. heritageisation), ko na ostanke preteklosti pripnemo določeno simbolno vrednost (Harvey, 2001; Bendix, 2009). Preučevanje dediščine tako ni v njeni materialnosti, temveč v raziskavi socialnih praks oziroma procesov, prek katerih ostankom preteklosti pripisujemo nove pomene. Pomembni so ideja, pomen, vrednosti, ki jih dediščina uteleša (Fakin Bajec, 2011, str. 69-70).

Najsplošneje sprejeta definicija dediščino dojema kot "sodobni kulturni proizvod, ki ga oblikuje zgodovina" (Tunbridge in Ashworth, 1996, str. 20). Je subjektivna, filtrira jo sedanjost, kadar koli ta sedanjost je, je obremenjena $\mathrm{z}$ vrednotenjem, povezana s procesom komodifikacije, poblagovljenja in tesno povezana s preteklostjo (Harvey, 2001, str. 327). Definirana je tudi kot korpus znanja in kot politični ter kulturni proces spominjanja, pozabljanja in komunikacije (Smith, 2006; Smith in Akagawa, 2009, str. 6). Ni je dediščine, ki ne bi bila povezana s kontroverznostjo, z nesoglasji, neskladnostjo in 
s kulturno ter identitetno politiko. Kot je dediščina povezovalna, je tudi izključevalna, še posebej v nacionalnem okviru, ki predvideva kulturno homogenost. Nacionalna dediščina povezuje vsakega posameznika v širšo nacionalno zgodbo, vendar tisti, ki se z njo ne morejo poistovetiti, ostanejo zunaj, ne pripadajo (Hall, 2008; Smith, 2006; Tunbridge in Ashworth, 1996). Zato govorimo o hegemonskem oz. avtoriziranem/pooblaščenem dediščinskem diskurzu in podrejenem, alternativnem, obrobnem, utišanem diskurzu (Smith, 2006). Tudi najbolj "velika« dediščina je neskladna in sporna, zato ideja »univerzalnih" vrednot ne vzdrži (Smith in Akagawa, 2009, str. 5).

Drugačen način razumevanja dediščine od zgoraj navedenega kritično antropološkega, ki refleksivno opazuje, kako družba misli dediščino, je aplikativni pristop v rokah muzealcev, konservatorjev, svetovalcev za razvoj turizma itd., ki so v nekaterih pogledih videni kot ustvarjalci oziroma izumitelji dediščine (Fakin Bajec, 2011, str. 13). Trk obeh pogledov je opazen v pogledu na avtentičnost dediščine.

$\mathrm{S}$ pojmom avtentičnosti je $\mathrm{v}$ evropski etnologiji povezan pojem folklorizma, ki naj bi označeval nepravo, drugotno folkloro, »aplicirano folkloro«, »ljudsko kulturo iz druge roke«, ponaredek, banalizacijo, »ko nekaj delamo, kot da bi«, ko obujamo nove izraze prek starih oblik, pri čemer se pri selekciji preteklosti sklicujemo na tradicionalnost, unikatnost, izvirnost, tipičnost (Poljak Istenič, 2013, str. 141-146; Bausinger, 2004, str. 158; Bogataj, 1992, str. 16). Folklorizem oživlja navadno že pozabljene oblike ljudske kulture (plese, pesmi, glasbo, šege itd.) v obliki znanstvene rekonstrukcije ali z vključevanjem v turistične prireditve. Pri tem se folklora postavi izven izvornega okolja, spremeni se njena funkcija ter njen simbolni in socialni pomen, prvotno povezan z lokalnim, se prenese na širšo raven, pokrajino ali narod. V 19. stoletju je, recimo, narodno zavedno meščanstvo nosilo "narodno nošo« kot simbol slovenstva, pri čemer se praznična obleka kmečkega človeka iztrga iz izvirnega okolja in dobi nov pomen, v 20. stoletju pa postane obleka folklorističnih prireditev. Kljub negativnim obsodbam folklorizma mu strokovnjaki priznavajo, da je iz pozabe iztrgal marsikaj, kar bi bilo drugače pozabljeno (Stanonik idr., 2007; Stanonik, 1990, str. 32-34).

V sodobnosti raziskovalci ne ločujejo več med dobrimi, koristnimi, legitimnimi tradicijami ter na drugi strani »umetnimi«, škodljivimi, "neavtentičnimi«, saj so pojmi naravnega in avtentičnega tuji kulturnim oblikam, ki so vse »konstrukcije» (Bausinger, 2004; Mu- 
gnaini, 2004, str. 40-41). »Zamrznjene« skupnosti ne obstajajo. Prednost tradicije pomeni stalno proizvajanje, spreminjanje in prilagajanje sodobnemu življenju, da bi ostala pomenljiva za člane skupnosti. Včasih tradicije tudi izginejo, predvsem takrat, ko izgubijo pomen za ljudi in utrjevanje skupinske identitete. Zato je potrebno opustiti tri stereotipe o tradiciji: da nima nič s sedanjostjo, da naj bi jo ljudje sprejemali zgolj pasivno in da naj bi bila zgolj prenos preteklosti $\mathrm{v}$ sedanjost v poskusu iztrganja pozabi (Sims in Stephens, 2005; Lenclud, 2004).

Ker je tradicija ves čas podvržena spremembam, je avtentično nemogoče definirati. Potrebo po iskanju avtentičnosti je porodila modernizacija z odtujitvijo človeka od številnih družbenih vrednot, dela, narave, humanosti, kolektivnosti, lokalnosti, tradicionalnosti. Najbolj se to izraža v turizmu, kjer avtentičnost implicira tradicionalno kulturo, občutek izvirnosti, dejanskosti in enkratnosti (Poljak Istenič, 2013, str. 106). V turizmu se avtentičnost prezentacije dediščine meri po treh osnovnih merilih: času, kraju in družbenemu okolju (oziroma lokalnosti) predstavljene kulturne oblike. Za neavtentične prezentacije veljajo časovna (npr. pustne prireditve poleti), krajevna (npr. kurenti v Piranu, Kopru, Planici) in družbena (npr. kmečka »ohcet« v mestnem okolju).

Tudi pri trženju avtentičnosti v turizmu ali avtentičnosti v marketinški strategiji gre za proces komodifikacije. Strokovnjaki se zavedajo, da pri tem ne gre za nekaj nespremenjenega, nedotaknjenega iz roda v rod, temveč kvečjemu za bolj ali manj "pristen ponaredek«, bolj ali manj popolno simulacijo nečesa drugega (Grafenauer, 2009, str. 12-13). Na turistične prostore se gleda kot na odrom podobne kraje, kjer turist izkusi »avtentičnost«. Ko gostitelj skuša narediti svojo kulturo mikavno za turista, jo spremeni, zato temu pravimo "uprizorjena avtentičnost «. Ko kultura postane objekt turizma, se segmentira in loči od »domače« kulture, se njena "avra avtentičnosti« zmanjša. Nekateri avtorji govorijo tudi o »avtentični iluziji«. Nesnovna dediščina namreč avtentičnosti nima. Njeno konstanto poustvarjanje, različno apliciranje, spremenljivost pomena, spremenjeno izvajanje skozi čas je v nasprotju s tem, kar se dojema kot avtentično - kot ukoreninjeno, zvesto, fiksirano. Nekateri predlagajo opustitev termina avtentičnosti, saj se ne more nanašati na natančno reprezentacijo preteklosti, temveč na podobo, ki jo proizvajajo nostalgične prakse in industrija dediščine. Drugi avtorji pa zagovarjajo pojem, 
ki naj ostane kot termin za osmišljanje izkušenj turistov (Poljak Istenič, 2013, str. 103-108; Scounti, 2009).

\section{Kreativni turizem}

Kreativnost je »IN«: ni samo »vroča«, je tudi »kul« (Richards, 2011, str. 1225). Kreativnost in kreativni proces sta civilizacijsko gibalo družbenega napredka, tako v znanosti, umetnosti, industriji kot tudi $\mathrm{v}$ turizmu. Sta ključna pri ustvarjanju nove vednosti in znanja, novih doživetij in izkušenj. Kreativnost bi morala predstavljati temeljno izhodišče razvoja vseh zvrsti turizma, ne le kreativnega.

Kreativni turizem ni nič novega, meni Richards (2009), saj se ljudje na dopustu že dolgo ukvarjajo z ustvarjalnimi, izobraževalnimi in učnimi aktivnostmi. Razlika je v tem, da je ta vrsta turizma postala tako pogosta, da jo je mogoče prepoznati pod novo oznako: kreativni turizem. Kreativnost je postala »buzzword «, beseda ali fraza v razvojnem kontekstu - od kreativnih industrij, kreativnih razredov, kreativne ekonomije, kreativnih mest, kreativnega poslovanja, kreativnega upravljanja do kreativnega turizma (Jelinčić in Žuvela, 2012, str. 78). Kreativni turizem vpliva na razvoj turističnih modelov, programov in storitev v prihodnosti. Usmerjen je v kreiranje diverzificirane proizvodnje in (u)porabe izkušenj kot gibala gospodarskega, družbenega in kulturnega razvoja, prioritetno usmerjenega k lokalnimi skupnostim in lokalnim kulturam. Na splošno obstajata dva temeljna modela implementacije kreativnega turizma: uporaba kreativnosti kot turistične aktivnosti in uporaba kreativnosti kot ozadja za turizem (Jelinčić in Žuvela, 2012, str. 78).

Literatura o turističnih raziskavah kreativni turizem omenja kot obliko posebnega zanimanja za turizem, ki v nasprotju s tradicionalnim množičnim kulturnim turizmom omogoča širšo udeležbo turistov v lokalnih skupnostih in njihovih snovnih ter nesnovnih kulturnih dobrinah. Hitra rast kreativnega turizma se kaže tudi v znatno povečanem številu študij, objav in poročil, posvečenih tej temi, ki v zadnjih letih strmo narašča (Richards, 2015b).

Korenine koncepta kreativni turizem segajo v sredino devetdesetih let prejšnjega stoletja in so povezane $\mathrm{z}$ iskanjem načinov povečane prodaje rokodelskih izdelkov turistom (Richards, 2005). Raziskovalci in praktiki so pod okriljem transnacionalnega projekta EUROTEX (1997-1999), ki je povezoval obrti in turizem, razmišljali o ohranjanju rokodelske in obrtne proizvodnje skozi učinkovitejše trženje 
visokokakovostnih ročno izdelanih lokalnih (tekstilnih) izdelkov za turiste. Le-te je zanimala rokodelska izkušnja, zato se jih je vključevalo v proizvodni proces skozi učenje specializiranih tehnik proizvodnje (Richards, 2005; 2010). Te osnovne ideje so postale navdih za vse tisto, kar bi kasneje poimenovali kot "kreativni turizem « (Richards, 2009).

Definicije kreativnega turizma se spreminjajo z razvojem kreativnega turizma samega (Richards, 2015c, str. 9). Richards in Raymond (2000) prvič opredelita kreativni turizem kot turizem, ki obiskovalcem ponuja razvoj njihovega lastnega ustvarjalnega potenciala $\mathrm{z}$ aktivnim sodelovanjem na tečajih in učnih izkušnjah, značilnih za počitniško destinacijo, na kateri se izvajajo. unEsco ga opredeli kot turistično nišo, kot potovanje, usmerjeno $\mathrm{k}$ angažiranemu in pristnemu doživetju, s participativnim učenjem umetnosti, dediščine ali posebnosti kraja in z zagotavljanjem povezave s tistimi, ki prebivajo $\mathrm{v}$ tem kraju in ustvarjajo to življenjsko kulturo (UNESCO, 2006, str. 3).

Richards (2009, str. 84-85) izpostavi, da kreativni turizem postaja vse pomembnejši, ker:

- kulturni turizem postaja množični turizem,

- kulturni turisti postajajo izkušenejši in zahtevajo zanimivejše izkušnje,

- destinacije iščejo alternative tradicionalnim turističnim produktom.

V nadaljevanju (2009, str. 84-85) izpostavi tudi pomen kreativnosti v turizmu, ker:

- ustvarja atmosfero,

- vzpostavlja potrebo po samorazvoju ljudi,

- ustvarja neposredno povezavo med kulturo turista in kulturo destinacije,

- se izogiba problemom »izgorelosti« dediščine in serijskim reprodukcijam.

Kulturnoturistične metropole sveta, kot npr. Barcelona, Pariz, London, Dunaj, Praga, Berlin, tekmujejo na globalnem turističnem trgu za svojo prepoznavnost, ki z vidika turističnih doživetij postaja vse bolj unificirana. Bitka za prepoznavnost kreatorje kulturnoturističnih politik in podjetniških praks pripelje do inovativnih razvojnih modelov turizma, med katere sodi tudi kreativni turizem, usmerjen $\mathrm{v}$ 
poudarjanje in komuniciranje lokalne kulture in vsakdanjega načina življenja, $\mathrm{v}$ tesnejše povezovanje lokalnega prebivalstva in turistov, v skupno kreiranje doživetij, v organizirano mreženje ponudnikov različnih oblik kreativnosti.

Kreativni turizem prinaša priložnosti za razvoj ne le velikih, ampak tudi manjših mest (Richards, 2019) in omogoča turistom, da so na različne načine povezani in vpeti $\mathrm{v}$ spoznavanje lokalne kulture (Carvalho, 2014), kjer lahko lokalno prebivalstvo zasluži denar direktno od turistov (Richards in Russo, 2014). Identiteta lokalne skupnosti postaja gonilo razvoja kreativnega turizma skozi interaktivno ustvarjanje turističnih doživetij in izkušenj. Richards v kontekstu osnovnih usmeritev kreativnega turizma izpostavlja Konfucijev pregovor: "Slišim in pozabim. Vidim in se spomnim. Naredim in razumem.« (Richards, 2015a, str. 1) »Čuti kot lokalec« bi zato lahko razumeli kot enega od izhodiščnih postulatov kreativnega turizma.

Lokalna kultura predstavlja priložnost za soočenje in spoznavanje vsakdanjega načina življenja in kulture, stik s "pristno «, »avtentično« izkušnjo, $\mathrm{z}$ »dušo naroda «, kot bi se izrazili etnografi že v 19. stoletju. Načelo »jej kot lokalci«, "pij z lokalci« ipd. ponuja številne priložnosti za interakcijo z lokalnimi skupnostmi. Kreativni turist daje prednost lokalnim izkušnjam in lokalnemu pred globalnim. Stopnja identifikacije z lokalno kulturo je velika, izkušnja edinstvena, s čimer se povečuje privlačnost turističnih mest in destinacij. Richards (2009) ob tem izpostavlja obstoj povezav med ustvarjalnostjo in privlačnostjo krajev. Turistično privlačnejši so tisti kraji, ki so tudi kreativnejši (Barcelona, Berlin ...).

Kreativni turizem $\mathrm{v}$ ospredje postavlja vsakdanjo in popularno kulturo kot elementa turističnega produkta. Richards (2009) izpostavi tudi pomen kreativnih prostorov na kreativnih destinacijah, kot so inovativne oblike nastanitev (posebni hoteli ali hotelske verige), ki služijo tudi komuniciranju kreativnosti, umetnosti, oblikovanja ..., pa tudi pomen prireditev, kjer turisti in prebivalci postajajo partnerji pri ustvarjanju kulturne izkušnje, ki temelji na tradiciji kot viru navdiha za sodobno ustvarjalnost. Kljub navidezni konceptualni butičnosti kreativnega turizma pa le ta ni zasnovan samo za manjše, ampak tudi za večje deležnike, ne le za ekskluzivne, ampak tudi za paketne aranžmaje.(Richards, 2009)

Razvoju koncepta kreativnega turizma botruje tudi »masifikacija « kulturnega turizma, ki se sprva pojavlja kot alternativna oz., kot se 
slikovito izrazi Richards (2009), kot "protistrup« množičnemu in nizkokakovostnemu turizmu na številnih destinacijah sveta. Skozi desetletja postane razmah množičnega kulturnega turizma po vsem svetu žrtev svojega lastnega uspeha (Richards, 2013). Porast množičnega kulturnega turizma $v$ več krajih sveta prinaša več negativnih učinkov, kot so prenaseljenost, okoljski problemi, degradacija lokalne kulture ipd. (Richards, 2013)

Težave množičnega kulturnega turizma so prišle najbolj do izraza v ikoničnih historičnih okoljih, kot npr. v Benetkah ali Dubrovniku, kar se odraža v vse slabši kakovosti življenja lokalnega prebivalstva kot tudi v poslabšanju doživetja teh edinstvenih lokalitet zaradi množičnosti turistov, ki v mesto pridejo le za nekaj ur. Priljubljenost, vseprisotnost in razširjenost kreativnega turizma generira produkcijo univerzalnih načinov komuniciranja dediščine in kulture, ki kot "copy-paste« modeli turistom v različnih krajih sveta ponujajo identična doživetja in izkušnje, npr. vodene oglede mestnih znamenitosti $\mathrm{z}$ avtobusi ipd. Richards (2013) za poimenovanje tega pojava parafrazira Ritzerjevo McDonaldizacijo družbe (1993), in sicer z izrazom "McKulturizacija» (angl. McCulturization).

Kulturni turizem je zaznamoval turizem v urbanih okoljih, manj na podeželju, in bil usmerjen predvsem $\mathrm{v}$ t.i. visoko kulturo, k ikoničnim znamenitostim, dediščinskim atrakcijam (muzeji, galerije, spomeniki) in megadogodkom. Kreativni turizem predstavlja odmik od tradicionalnih modelov dediščinskega in kulturnega turizma, odmik od »visoke kulture« k popularni kulturi in kulturi vsakdanjega življenja.

Porast zanimanja za kreativni turizem po celem svetu (Richards, 2015b, str. 20-32; 2018a) časovno sovpada z UNesco-vo konvencijo o varovanju nesnovne kulturne dediščine (2003). Vključevanje različnih področij nesnovne dediščine in kulture v turistično ponudbo predstavlja pomembno konceptualno izhodišče kreativnega turizma, s čimer se odpirajo številne priložnosti, a hkrati tudi pretijo številne nevarnosti pri izkoriščanju lokalnih identitet pri razvoju turizma v lokalnih skupnostih, tako v mestih kot na podeželju. Participativni pristop postaja eden od zaščitnih znakov in temeljev razvoja kreativnega turizma, usmerjenega v ustvarjanje izkušenj in doživetij.

Kreativni turizem bo v bližnji prihodnosti verjetno ostal niša znotraj kulturnega turizma (Richards, 2011), pomembno vlogo pri njegovem dosedanjem in prihodnjem razvoju pa predstavljajo tudi spe- 
cializirane mreže, kot npr. Creative Tourism New Zealand, Creative Tourism Barcelona, Creative Tourism Austria ... Med seboj se razlikujejo po različnih načinih povezovanja (mreženje kreativnih podjetij, posredništvo v povezovanju kreativnih producentov s potencialnimi ljudmi (turisti) iz drugih delov sveta ipd.). Creative Tourism Network (CTN) (http://www.creativetourismnetwork.org) je mednarodna mreža za razvoj kreativnega turizma po celem svetu, ki sta jo leta 2010 ustanovila Caroline Couret in Greg Richards, koinovatorja koncepta kreativnega turizma. Znotraj cтN deluje Creative Tourism Academy, ki izvaja specializirana izobraževanja in svetovanja po celem svetu; razvila se je iz platforme Barcelona Creative Tourism leta 2005.

In kdo so kreativni turisti? S.-K. Tan idr. (2014) izpostavljajo pet razločevalnih skupin kreativnih turistov: (1) iskalci novosti, (2) iskalci novih znanj in spretnosti, (3) tisti, ki želijo na potovanjih osebnostno rasti skupaj s partnerji, (4) tisti, ki se zavedajo zelenih vprašanj, (5) iskalci sprostitve. Spet drugi pa kreativnega turista označijo kot ekoprijaznega popotnika in humanista, zainteresiranega za vzpostavljanje odnosov "peer-to-peer" (Interview of Carline Couret about the Creative Tourism, 2019).

N. Duxbury in Richards (2019) izpostavljata štiri razvojne faze kreativnega turizma (od 1.o do 4.0), ki se ne razvijajo ena za drugo, ampak vzporedno. Razvojni lok sega od pridobivanja izkušenj skozi formalnejše oblike učenja do kreiranja doživetij na destinaciji, povezovanja turizma in kreativnih industrij, vzpostavljanja relacijskih mrež in ustvarjanja izkušenj, ki pomagajo zmanjševati kulturne in jezikovne prepreke med ljudmi.

Kritično zaskrbljenost glede koncepta kreativnega turizma izpostavljata D. A. Jelinčić in A. Žuvela, ki se sprašujeta, kako daleč lahko gre razvoj kreativnega turizma. Izpostavljata izkušnje, ki kažejo, da so bile številne lokalne tradicije spremenjene, da so izpolnile pričakovanja obiskovalcev, kar je privedlo do izumljanja tradicije ali izmišljene avtentičnosti (Jelinčić, 2010, str. 47-48); poleg tega pa sodobne izkušnje razvoja turizma kažejo nenaklonjenost domačinov do turistov, saj vdirajo v njihovo vsakdanje življenje. Ali se je torej treba izogibati ali celo prepovedati turistične participativne dejavnosti, če spremenijo ali posegajo v lokalno kulturo? (Jelinčič in Žuvela, 2012) Kreativni turizem bi moral turistom prinašati edinstvene vrednosti, ki spodbujajo lokalno identiteto, $v$ kateri se naravni, kulturni in oseb- 
ni viri ne manipulirajo in izkoriščajo, temveč cenijo in bogatijo (Jelinčič, 2012, str. 87-88).

\section{Zaključek}

S stališča celostnega, holističnega razumevanja kulture je turizem ipso facto kulturni, kar pomeni, da ga ne moremo izzvzeti iz kulture. Turizem je kulturni turizem kot fenomen. Tovrstni pogled je najbližje izhodiščem trajnostne in s tem odgovorne naravnanosti.

V pridevniški obliki je »kulturni turizem « zgolj eden v nizu turizmov, partikularen, notranje fragmentiran, podvržen modni marketinški (hiper)produkciji, v kateri se posamezni elementi kreirajo $\mathrm{v}$ interesu akumulacije kapitala in iskanja dobička, znotraj modelov "kreativnega uničenja» (Yang idr., 2019).

Ublagovljenje, konstrukcija dediščine, avtentičnost, kreativnost so procesi in ne statične entitete ali absolutne kategorije. V sedemdesetih letih, ki jih je zaznamoval vsebinski obrat v turističnih študijih kot odgovor na dominantne, na ekonomiji temelječe, raziskave turizma iz 50-ih in 6o-ih let minulega stoletja, je izšel tudi prvi zbornik besedil s področja antropologije turizma. V njem je Greenwood (1977) sprožil širšo debato o ublagovljenju kulture v turizmu, s poudarjenim naglasom na negativnih vidikih, ki jih je dobro desetletje kasneje, ko je izšel dopolnjen zbornik, sicer do neke mere revidiral. Že v izvirnem besedilu pa se je lotil tudi konceptov avtentičnosti in kreativnosti. Leto prej je izšla, še danes izjemno vplivna, monografija Deana MacCannella (1976), v kateri je avtor lansiral tezo, da sodobni odtujeni turisti potujejo $\mathrm{v}$ iskanju avtentičnosti, in predstavil primere "uprizorjene avtentičnosti«. Idejo uprizarjanja je prevzel iz simbolnega interakcionizma, konkretno iz raziskav Ervinga Goffmana o prezentaciji v vsakdanjem življenju, kjer so interakcije v javnem prostoru razdeljene na oder in zaodrje. Od MacCannelove knjige dalje so se razprave o avtentičnosti v turizmu dobesedno razbohotile in postale skorajda nepregledne. »Avtentičnost « je v akademskih razpravah dobila raznorodne pridevnike, kot so: topla, hladna, objektivna, indeksirana, nominalna, ikonična, eksistencialna - slednji bi bolj ustrezal izraz izkustvena, ker poudarja izkustveno percepcijo avtentičnosti posameznega turista in ne njegove osebne avtentičnosti v eksistencialnem smislu, kot jo je razumel Heidegger in na katero se nekateri avtorji sicer nominalno sklicujejo. Vprašanje o smiselnosti razprave o avtentičnosti oz. konceptualne rabe avtentičnosti, še 
posebej v povezavi s konstrukcijo, produkcijo in z interpretacijo dediščine je bilo v pričujočem poglavju že izpostavljeno. Tudi sodobne primere »kreativnega turizma « lahko pogledamo v historičnem kontekstu iskanja »alternativnih" oblik turizma nasproti množičnemu turizmu, ki poteka že od 6o-ih let dalje. Takrat se je "alternativa" imenovala projekt malega obsega (angl. small-scale project), vsebinsko pa je bila ravno tako osrediščena na participatornost - čeravno ta termin ni bil uporabljen - in na lokalne kulture. Temeljna sprememba od 6o-ih let do danes se tako zdi bolj v številčnem obsegu turizma kot pa v obliki in vsebini "alternativ«. Richardsovo poimenovanje "kreativnega turizma « nima reference na zgodovino, ravno tako kreativnosti ne razume $\mathrm{v}$ filozofskem smislu. Za interpretacijo ne uporablja lastnih raziskav in se večinoma naslanja na izvorno ekonomske modele, ki jih geografsko predela v smislu prostorskih kategorij; ob tem prakticira, kot sam pravi, "foucaultovsko intelektualno arheologijo «, ${ }^{2}$ se pravi izposojo od drugih avtorjev. Po formaciji torej ne sodi $\mathrm{v}$ polje humanistične obravnave kulturnega turizma, čeprav se občasno informativno referira tudi na antropologijo (Richards, 2018a).

Na kratko smo v poglavju želeli orisati nekatere od temeljnih zagat sodobnih razprav o kulturnem turizmu, ki se nahajajo na različnih disciplinarnih bregovih. Če se vrnemo k uvodno izpostavljenima zbornikoma, lahko ugotovimo, da je poslovnoupravljalski zbornik o kulturnem turizmu že dočakal ponatis, medtem ko ga humanistični po vsej verjetnosti ne bo, kar zvesto odseva stanje na področju raziskovanja, akademske produkcije in moči v turizmu. V kontekstu povečane globalne strukturne neenakosti, v katero je turizem umeščen in jo nemalokrat poglablja, so poslovnoupravljalski modeli brez humanističnih uvidov ali, če rečemo drugače, brez culturae animi, verjetneje kot ne, obsojeni na izvotljeno sklicevanje na načelo trajnosti in daleč od zavez odgovornega turizma.

\section{Literatura}

Bauman, Z. (1999). Culture as praxis. Sage.

Bausinger, H. (2004). Per una critica alle critiche del folklorismo. V P. Clemente in F. Mugnaini (ur.), Oltre il folklore: Tradizioni popolari e antropologia nella società contemporanea (str. 145-159). Carocci.

2. Osebna komunikacija z Gregom Richardsom na University of Applied Sciences, Breda, 9. januar 2020. 
Bendix, R. (2009). Heritage between economy and politics: An assesment from the perspective of cultural anthropology. V L. Smith in N. Akagawa (ur.), Intangible heritage (str. 253-269). Routledge.

Carvalho, R. (2014). A literature review of the role of cultural capital in creative tourism. V J. Santos, M. Correia, M. Santos in F. Serra (ur.), Contemporary issues in tourism in management studies (тмs Conference Series, str. 17-28). University of The Algarve.

Du Cros, H., in McKercher, B. (ur.). 2015. Cultural tourism. Routledge.

Duxbury, N., in Richards, G. (2019). Towards a research agenda for creative tourism: Developments, diversity, and dynamics. V N. Duxbury in G. Richards (ur.), A research agenda for creative tourism (str. 182192). Edward Elgar.

Eriksen, T. H. (2001). Majhni kraji, velike teme. Aristej.

Fakin Bajec, J. (2011). Procesi ustvarjanja kulturne dediščine: Kraševci med tradicijo in izzivi sodobne družbe. Založba zRC.

Fang, W. (2019). Modern notions of civilization and culture in China. Palgrave McMillan.

Grafenauer, B. (2009). Turistična geografija in kulturna dediščina. Zavod IRC. http://www.impletum.zavod-irc.si/docs/Skriti_dokumenti/ Turisticna_geografija_in_kulturna_dediscina-Grafenauer_1.pdf

Greenwood, D. J. (1977). Culture by the pound: An anthropogical perspective on tourism as cultural commoditization. V Valene L. Smith (ur.), Hosts and guests: The anthropology of tourism (str. 129-138). University of Pennsylvania Press.

Hall, S. (2008). Whose heritage? Un-settling 'the heritage,' reimagining the post-nation. V R. Harrison, G. Fairclough, J. H. J. Jameson in J. Shofield (ur.), The heritage reader (str. 219-228). Routledge.

Harvey D. C. (2001). Heritage pasts and heritage presents: Temporality, meaning and the scope of heritage studies. International Journal of Heritage Studies, 7(4), 319-338.

International Council on Monuments and Sites. (1999). International cultural tourism charter. https://www.icomos.org/charters/tourism _e.pdf

Interview of Carline Couret about the creative tourism. (2019). Creative Tourism Network. https://www.creativetourismnetwork.org/ interview-of-caroline-couret-about-the-creative-tourism

Jelinčić, D. A. (2010). Kultura u izlogu: kratki vodič za upravljanje kulturnim dobrima. MeandarMedia.

Jelinčić, D., in Žuvela, A. (2012). Facing the challenge? Creative Tourism in Croatia. Journal of tourism Consumption and Practice, 4(2), 78-90.

Koželj, Z. (2005). Nesnovna kulturna dediščina in njeno varstvo. V D. Prešeren in N. Gorenc (ur.), Nesnovna kulturna dediščina (str. 8-12). Zavod za varstvo kulturne dediščine Slovenije. 
Kroeber, A. L., in Kluckhohn, C. (1952). Culture: A critical review of concepts and definitions (Papers of the Peabody Museum of American Archaeology and Ethnology). Cambridge, ma.

Lenclud, G. (2004). La tradizione non è più quella di un tempo. V P. Clemente in F. Mugnaini (ur.), Oltre il folklore: Tradizioni popolari e antropologia nella società contemporanea (str. 123-134). Carocci.

MacCannell, D. (1976). The tourist: A new theory of the leisure class. Schocken Books.

Mauss, M. (1996). Esej o daru in drugi spisi. Studia Humanitatis.

Mugnaini, F. (2004). Introduzione: Le tradizioni di domani. V P. Clemente in F. Mugnaini (ur.), Oltre il folklore: Tradizioni popolari e antropologia nella società contemporanea (str. 11-72). Carocci.

Orel Frank, T., in Medarić, Z. (2018). Cultural tourism from an academic perspective. Academica Turistica, 11(2), 101-110.

Poljak Istenič, S. (2013). Tradicija $v$ sodobnosti. Založba zRC.

Richards, G. (2005). Textile tourists in the European periphery: New markets for disadvantaged areas? Tourism Review International, 8(4), 323-338.

Richards, G. (2009). Creative tourism and local development. V R. Wurzburger, A. Pattakos in S. Pratt (ur.), Creative tourism: A global conversation (str. 78-90). Sunstone Press.

Richards, G. (2010). EuRotex: Trans-national partnership linking crafsand tourism. V Joining forces: Collaborative process for sustainable and competitive tourism (str. 83-88). World Tourism Organization.

Richards, G. (2011). Creativity and tourism: The state of the art. Annals of Tourism Research, 38(4), 1225-1253.

Richards, G. (2013). Tourism development trajectories - From culture to creativity? V M. Smith in G. Richards (ur.), The handbook of cultural tourism (str. 297-303). Routledge.

Richards, G. (2015a, 3. november). Creative tourism: New opportunities for destinations worldwide? [Predstavitev na konferenci]. World Travel Market Conference on 'Creative Tourism: All that you need to know about this growing sector,' London, Velika Britanija.

Richards, G. (ur.). (2015b). Creative tourism bibliography. https://www .researchgate.net/publication/325975867_Creative_Tourism _Bibliography

Richards, G. (2015c). Creative tourism trend report (1. zvezek). Association for Tourism and Leisure Education and Research.

Richards G. (2018a). Cultural tourism: A review of recent research and trends. Journal of Hospitality and Tourism Management, 36, 12-21.

Richards, G. (2018b, 7. december). Panorama of creative tourism around the world [predstavitev na konferenci]. Seminário International de Turism Criativo, Recife, Brazilija. 
Richards, G. (2019). Creative tourism: Opportunities for smaller places? Tourism in Management Studies, 15, 7-10.

Richards, G., in Raymond, C. (2000). Creative tourism. ATLAs News, (23), 16-20.

Richards, G., in Russo, A. P. (ur.). (2014). Alternative and creative tourism. Association for Tourism and Leisure Education.

Ritzer, G. (1993). The McDonaldization of society. Pine Forge Press.

Scounti, A. (2009). The authentic illusion: Humanity's intangible cultural heritage, the Moroccan experience. V L. Smith in N. Akagawa (ur.), Intangible heritage (str. 74-92). Routledge.

Selwyn, T. (2013). Hospitality. V M. Smith in G. Richards (ur.), The Routledge handbook of cultural tourism (str. 172-176). Routledge.

Sims, M. C., in Stephens, M. (2005). Living folklore: An introduction to the study of people and their traditions. Utah State University Press.

Smith, L. (2006). Uses of heritage. Routledge.

Smith, L., in Akagawa, N. (2009). Introduction. V L. Smith in N. Akagawa (ur.), Intangible heritage (str. 1-9). Routledge.

Smith, M., in Richards, G. (ur,). 2013. The Routledge handbook of cultural tourism. Routledge.

Smith, L., Waterton, E., in Watson, S. (ur.). (2012). The cultural moment in tourism. Routledge.

Stanonik, M. (1990). O folklorizmu na splošno. Glasnik SED, 3o(1/4), 2042.

Stanonik, M., Terseglav, M., in Slavec Gradišnik, I. (2007). Folklorizem. V A. Baš (ur.), Slovenski etnološki leksikon (str. 131-132). Mladinska knjiga.

Tan, S.-K., Luh, D. B., in Kung, S. F. (2014). A taxonomy of creative tourists in creative tourism. Tourism Management, 42, 248-259.

The Kinks. (1965). Dedicated follower of fashion. https://www.azlyrics .com/lyrics/kinks/dedicatedfolloweroffashion.html

Tunbridge, J. E., in Ashworth G. J. (1996). Dissonant heritage: The management of the past as a resource in conflict. Wiley.

Tylor, E. B. (1871). Primitive culture: Researches into the development of mythology, philosophy, religion, language, art and custom. Murray.

unEsco. (1972). World heritage convention. https://whc.unesco.org/en/ convention/

UNESCO. (2001). Universal declaration on cultural diversity. http:// portal.unesco.org/en/ev.php-URL_ID=13179\&URL_DO=DO _TOPIC\&URL_SECTION=201.html

UNESCO. (2003). Convention for the safeguarding of the intangible cultural heritage. https://ich.unesco.org/en/convention

UNESCO. (2006). Towards sustainable strategies for creative tourism (Discussion report of the planning meeting for 2008 International Con- 
ference on Creative Tourism, Santa Fe, New Mexico, usa, October 25-27, 2006).

UNESCO. (2008). Cultural tourism definition. http://portal.unesco.org/ culture/en/ev.php-URL_ID=36700\&URL_DO=DO_TOPIC\&URL _SECTION=201.html

UNESCO. (2014). The Hangzhou declaration: Placing culture at the heart of sustainable development policies. http://unesdoc.unesco.org/ images/o022/002212/221238m.pdf

Williams, R. (1958). Culture and society 1780-1950. Chatto \& Windus.

Williams, R. (1983). Keywords: A vocabulary of culture and society. Oxford University Press.

Yang, X., Xu, H., in Wall, G. (2019). Creative destruction: The commodification of industrial heritage in Nanfeng Kiln District, China. Tourism Geographies, 21(1), 54-77.

World Tourism Organization. (B. 1.) Tourism and culture. https://www .unwto.org/tourism-and-culture 